\section{Pablo Neruda, Confieso que he vivido. Memorias}

Seix Barral, 2017, 516 páginas

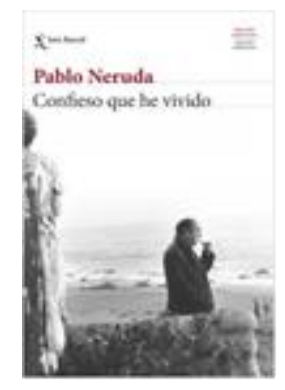

Darío Oses, editor de ésta versión extendida de las memorias de Pablo Neruda, señala en el prefacio de la obra, que ésta nueva edición permite proponer nuevas lecturas. A la sazón de tal afirmación, este comentario de Confieso que he vivido se hace desde un enfoque internacional, es decir, de lo que Pablo Neruda registró en este libro póstumo sobre su carrera diplomática y su experiencia como sujeto internacional.

Pablo Neruda -antes Ricardo Eliecer Neftalí Reyes Basoalto- cuenta en sus memorias, que se desempeñó como Cónsul en las ciudades de Rangoon, Colombo y Batavia ${ }^{1}$, entre los años 1927 y 1932. Esta estadía de cuatro años y más en el Oriente Lejano comenzaron de manera poco institucional, en realidad fue por amistad, confianza y gracias a una entrevista que un amigo le consiguió con el Ministro de Relaciones Exteriores, quién personalmente le consultó que lugar

\footnotetext{
1 Rangoon fue colonia británica y es la actual capital Myanmar, su estadía fue entre octubre de 1927 a diciembre de 1928. Colombo fue colonia británica y es la actual capital de Sri Lanka, antes Ceylán, su estadía fue entre enero de 1929 a mayo de 1930. Batavia fue colonia de los Países Bajos y es la actual Yakarta, capital de Indonesia, su estadía fue entre mayo de 1930 a febrero de 1932.
}

le gustaría como destino, contestando Rangoon, por ser la ciudad que "nunca había oído ni leído antes” (pág. 85). Su viaje para asumir como Cónsul fue largo y accidentado, en Shanghái lo asaltaron y en Tokio quedó sin dinero, recurriendo al Cónsul de Chile en cada ciudad para que lo auxiliara, no obstante, como él lo describe, ninguno fue diligente, por el contrario, fueron indiferentes. Quizás estos dos hechos fueron los que suscitaron de manera temprana su relación con el Servicio Exterior de Chile, la cual se vio reflejada en mutuos desentendimientos, reciprocas fricciones y bilaterales enemistades.

Durante estos años, el funcionario Reyes Basoalto vivió varios hechos destacables. Uno de ellos, fue una conversación con un colega alemán, a quién le presentó sus inquietudes sobre un nuevo líder germano de apellido Hitler, quién, de cuando en cuando, adquiría relevancia pública. Directamente le preguntó si ese líder llegaría al poder, recibiendo como respuesta la palabra "imposible" (pág. 128).

Las páginas sobre su estadía consular en el Oriente Lejano, hoy Asia del Sudeste, transmiten su experiencia con la economía colonialista, donde la potencia dominante explotó a la localidad dominada sin generar algún tipo de crecimiento o desarrollo local. Además, dentro de sus experiencias pudo conocer y vivir la cultura del apartheid, donde la pigmentación de la piel fue la base de la estratificación de las clases sociales y del acceso a una mejor vida material.

Luego de volver a Chile, nuevamente el funcionario Reyes Basoalto cumplió funciones consulares, esta vez en Buenos 
Aires, Barcelona, Madrid y Paris². En los años que estuvo en España, se integró al cenáculo artístico madrileño, y durante la Guerra Civil Española tomó postura por el bando Republicano, promovió internacionalmente la solidaridad para con ellos, hizo la campaña del desprestigio contra el franquismo e ideológicamente se declaró comunista. Sin embargo, el ser Cónsul y Activista no fue bien visto por el Servicio Exterior, y como lo detalla en el libro, éste "decidió alejarme de mi cargo" (pág. 149).

Los capítulos España en el Corazón y Salí a buscar caídos pormenorizan lo que vivió y lo que hizo durante la guerra. De esto, lo más destacado y apasionante, fue su comisión consular en Paris, donde fue enviado, como lo precisa, para dar cumplimiento a la más noble misión que ejerció en su vida "la de sacar españoles de sus prisiones y enviarlos a mi patria” (pág. 167). No obstante, no todo fue fácil. La relación con los funcionarios de la Embajada se caracterizó, como cuando viajó al Oriente Lejano, por desentendimientos, fricciones $\mathrm{y}$ enemistades. Además, tal y como lo escribe, estando en plena faena para su cometido recibió un telegrama del Presidente de la República, Don Pedro Aguirre Cerda, quién desautorizaba la labor de llevar españoles a Chile "me pedía que de inmediato desmintiera tan insólita noticia” (pág. 173) lo cual produjo cierta alegría perversa entre sus colegas.

\footnotetext{
2 En Buenos Aires se desempeñó como Cónsul General entre agosto de 1933 y abril de 1934. En Barcelona fue Cónsul entre mayo y diciembre de 1934, siendo comisionado a Madrid, para asumir plenamente como Cónsul General en octubre de 1935 hasta diciembre de 1936. En Paris fue Cónsul Particular de Segunda Clase, entre marzo y diciembre de 1939.
}

Sin embargo, el funcionario Reyes Basoalto no se detuvo, continuó, los españoles arribaron y el Winnipeg, el barco que los trajo, se hizo famoso.

Los primeros años de los 1940s los vivió como Cónsul en el Distrito Federal de México ${ }^{3}$ En esta ciudad se reencontró con David Siqueiros, a quién invitó a pintar un mural a la Escuela México de Chillán, pero, según el mismo lo narra "el gobierno de Chile me pagó este servicio a la cultura nacional suspendiéndome de mis funciones de Cónsul por dos meses” (pág. 182) ya que el muralista estaba prófugo de la prisión, donde cumplía pena por participar en una incursión armada contra León Trotsky. Otro hecho destacable, similar a la conversación con su colega alemán, es que un día recibió a un grupo de japoneses que necesitaban viajar urgentemente de México a Chile, para allí embarcarse hacia Japón, su respuesta fue que se embarcaran en Manzanillo, México, pero ellos respondieron que los barcos japoneses no atracarían más en América del Norte. Para el funcionario Reyes Basoalto esto "no podía ser otra cosa que la participación de Japón en la guerra” (pág. 187) y si bien alertó a sus colegas de los países Aliados de su sospecha, estos subestimaron su aprensión. A la semana siguiente se produjo el ataque a Pearl Harbor.

Pero no fue la suspensión temporal de sus funciones, ni la Guerra Mundial lo que lo llevó a renunciar, fue, como él lo describe, cuando "el Ministerio de Relaciones Exteriores me llamara severamente la atención por lo que estimaba un desacato" (pág. 190) al crear una revista titulada

\footnotetext{
${ }^{3}$ En México se desempeñó como Cónsul General entre agosto de 1941 y agosto de 1943.
} 
Araucanía, que en su portada tenía el rostro de una mujer mapuche. Para aquel momento, existía una valoración por el eurocentrismo, inclusive como él mismo cuenta "el Ministerio me imponía que averiguara los orígenes raciales de las gentes, africanos, asiáticos o israelitas. Ninguno de estos grupos humanos podía entrar en mi patria” (pág. 190), en consecuencia, no era bien visto publicar una revista que tuviera una reseña a la nación mapuche. Ya fastidiado, renunció al Servicio Exterior, dejando su cargo de Cónsul y volviendo a Chile en agosto de 1943.

De vuelta a Chile, ingresó a la política partidista, fue electo Senador por la Agrupación provincial de Tarapacá y Antofagasta en marzo de 1945, entró a militar al Partido Comunista en Julio de ese año y fue Jefe de Campaña de Gabriel González Videla, quién resultó ganador de las elecciones. Sin embargo, la política partidista no fue un lugar llano para su vida, de hecho, el capítulo que lo narra se titula La patria en tinieblas, que en ésta edición incorpora un nuevo acápite, de nombre Retrato de un arribista, donde descalifica aún más a González Videla, como aparece en el libro "lo que el traidor traicionaría, lo que el vendedor vendería, lo que el renegado recibiría” (pág. 201) por perseguir y declarar finalmente ilegal al Partido Comunista en septiembre de 1948.

Frente a estos eventos, la respuesta del Senador Neruda se manifestó en una serie de discursos ${ }^{4}$ en contra del Presidente, que le significaron su paso a la clandestinidad y

\footnotetext{
${ }^{4}$ Los dos primeros son del 14 de octubre y del 10 de diciembre de 1947. El tercero, del 6 de enero de 1948 .
}

el autoexilio. Los tres años y más en el extranjero, comenzaron en marzo de 1949, cuando cruzó a caballo la Cordillera de los Andes. Ya en Argentina, debió solucionar un problema legal, se encontraba indocumentado y necesitaba viajar a Europa, por lo cual, recurrió a un antiguo amigo, otro escritor, otro latinoamericano, otro diplomático, otro futuro Premio Nobel de Literatura, al que le dijo "préstame tu pasaporte. Concédeme el placer de llegar a Europa transformado en Miguel Ángel Asturias” (pág. 215) y así fue, Pablo Neruda llegó con una identidad prestada a Europa, llegó como novelista y no como poeta.

Este autoexilio le permitió consolidarse como sujeto internacional, le dio un alcance global durante la Guerra Fría. Ya no era el funcionario Reyes Basoalto, tampoco el Senador Neruda, durante estos años tendría su estatus de Poeta, sería el sujeto internacional.

El capítulo Principio y fin de un destierro (pág. 222) relata sus viajes por el mundo, tanto por motivaciones artísticas, como los homenajes al poeta turco Nazim Hikmet y a los literatos rusos Boris Pasternak y Alexander Pushik; por el Premio Lenin de la Paz, del cual fue jurado, ganador y representante; o como Activista, como cuando se entrevistó con Sri Nehru, Primer Ministro de la India, a quién le expresó sus aprehensiones sobre el peligro atómico. En los capítulos siguientes, Pablo Neruda relata episodios realmente notables; uno de ellos fue una conversación con el Cosmonauta Guerman Totov, a quién le consultó si al navegar por el espacio divisó a Chile, recibiendo como respuesta "recuerdo unas cordilleras amarillas por Sudamérica. Se notaba que eran muy altas” (pág. 282); 
otro es su encuentro personal con Mao Tse Tung en Pekín, como él relata "al chocar nuestros vasos me miró con ojos sonrientes, y ancha sonrisa entre simpática e irónica” (pág. 368); y las veces que divisó al líder soviético Josef Stalin "siempre en el mismo punto: la tribuna que sobre la Plaza Roja se levanta llena de dirigentes de alto nivel” (pág. 368). Estos viajes, entrevistas y eventos, son solo para mencionar algunos que contienen sus memorias.

Cerrando este comentario, destaco tres eventos de las memorias, que se relacionan con la Política Exterior de Chile.

El primero, es la condecoración "Sol del Perú" que recibió en 1967 por parte del Presidente de ese país, Fernando Belaunde Terry. Pablo Neruda, señala que aceptó ser condecorado por su Poema Alturas de Macchu Picchu, y que tal gesto, era parte de las intenciones de buenas relaciones entre Chile y el Perú. Como él mismo lo escribe "entre los pueblos de Chile y Perú hay aún heridas sin cerrar. No solo los deportistas y los diplomáticos y los estadistas deben empeñarse en restañar esa sangre del pasado, sino también y con mayor razón los poetas, cuyas almas tienen menos fronteras que las de los demás” (Pág. 376).

El segundo, es el ataque que varios literatos cubanos hicieron contra su persona, dado principalmente, por asistir al Pen Club en Estados Unidos. Este ataque fue rechazado por el Partido Comunista de Chile, y fue quizás, el primer episodio de desencuentros entre la izquierda chilena y el Régimen de Castro durante el Siglo XX. En palabras textuales "ya no me acuerdo de los términos empleados por mis fiscales. Pero puedo decir que se erigían en profesores de las revoluciones, en domines de las normas que deben regir a los escritores de izquierda. Con arrogancia, insolencia y halago, pretendían enmendar mi actividad poética, social y revolucionaria” (Pág. 378). Junto con eso, Pablo Neruda califica de "descabellada” (pág. 382) la vía armada en sus memorias, mostrando la tensión entre la vía chilena al socialismo con la vía armada de Cuba.

El tercero, es una misión política del Estado de Chile, en donde como Embajador en Francia, debió defender la soberanía del cobre exportado frente a las potencias extranjeras. El Embajador Neruda recuerda que frente a la pretensión de embargo "no sólo los periódicos, las televisoras, las radios, se ocuparon preocupadamente de este asunto, sino que una vez más fuimos defendidos por una conciencia mayoritaria y popular. Los estibadores de Francia y de Holanda se negaron a descargar el cobre en sus puertos para significar su repudio a la agresión” (pág. 393).

Ésta edición extendida incluye 18 acápites nuevos, repartidos en los mismos 12 capítulos de la versión original, y muestran, que Pablo Neruda fue un poeta cuyo alcance como sujeto internacional fue amplio en la Poesía y en su postura política. Además, que en su vida no todo fue fácil y alegre.

Este comentario de Confieso que he vivido presenta diferentes estatus y roles del autor: el funcionario Reyes Basoalto, el Senador Neruda, el Poeta Pablo Neruda y el Embajador Neruda. Todos los cuales, llegan a comulgar, cuando el Premio Nobel de Literatura de 1971 le fue 
entregado al "poète chilien" (pág. 346). En ese momento, él alcanzó su punto culmine en su oficio de Poeta, como Pablo Neruda, pero también era Embajador en Francia, es decir, el punto culmine del funcionario Reyes Basoalto en su carrera Diplomática.

Pablo Rivas Pardo Cientista Político y Licenciado en Ciencia Política de la Universidad Diego Portales, Chile. Master of Art in International Relations and International Organizations de la Universidad de Groningen, Reino de los Países Bajos, p.rivas.pardo@gmail.com 